\title{
Mechanistic Investigation of the Pyrolysis of Brown Grease
}

\author{
Mansour H. Almatarneh (D), ${ }^{1,2}$ Imarat Y. Alnemrat, ${ }^{3}$ Reema A. Omeir, ${ }^{1}$ \\ Lawrence M. Pratt $\left(\mathbb{D},{ }^{4}\right.$ Thi Xuan Thi Luu, ${ }^{5}$ Minh Bui, ${ }^{5}$ and Dickens Saint Hilaire ${ }^{6}$ \\ ${ }^{1}$ Department of Chemistry, University of Jordan, Amman 11942, Jordan \\ ${ }^{2}$ Department of Chemistry, Memorial University, St. John's, NL A1B, Canada \\ ${ }^{3}$ Department of Chemistry, Yarmouk University, Irbid 21163, Jordan \\ ${ }^{4}$ Department of Chemistry and Environmental Science, Medgar Evers College. The City University of New York, \\ 1638 Bedford Ave, Brooklyn, NY 11225, USA \\ ${ }^{5}$ Department of Organic Chemistry, Ho Chi Minh University of Science, Ho Chi Minh City, Vietnam \\ ${ }^{6}$ Department of Chemistry and Chemical Technology, Bronx Community College, The City University of New York, Bronx, \\ NY 10453, USA
}

Correspondence should be addressed to Mansour H. Almatarneh; m.almatarneh@ju.edu.jo and Lawrence M. Pratt; lpratt@ mec.cuny.edu

Received 8 September 2020; Revised 26 September 2020; Accepted 18 November 2020; Published 22 December 2020

Academic Editor: Tianlong Deng

Copyright (c) 2020 Mansour H. Almatarneh et al. This is an open access article distributed under the Creative Commons Attribution License, which permits unrestricted use, distribution, and reproduction in any medium, provided the original work is properly cited.

\begin{abstract}
The conversion of brown grease using pyrolysis reactions represents a very promising option for the production of renewable fuels and chemicals. Brown grease forms a mixture of alkanes, alkenes, and ketones at a temperature above $300^{\circ} \mathrm{C}$ at atmospheric pressure. This work is a computational study of the detailed reaction mechanisms of brown grease pyrolysis using DFT methodology. Prior experimental investigations confirmed product formation consistent with a set of radical reactions with $\mathrm{CO}_{2}$ elimination, as well as ketone by product formation, CO forming reactions, and formation of alcohols and aldehydes as minor byproducts. In this work, computational quantum chemistry was used to explore these reactions in greater detail. Particularly, a nonradical pathway formed ketone byproducts via the ketene, which we refer to as Pathways A1 and A2. Radical formation by thermal decomposition of unsaturated fatty acids initiates a set of reactions which eliminate $\mathrm{CO}_{2}$, regenerating alkyl radicals leading to hydrocarbon products (Pathway B). A third pathway (Pathway C) is an alternative set of radical reactions, resulting in decarbonylation and formation of minor byproducts. The results of the calculations are in good agreement with recent experimental studies.
\end{abstract}

\section{Introduction}

The development of alternative and renewable energy and chemicals has been on the rise over the past decades. Recently, converting agricultural and forestry feedstocks (biomass) into multiple renewable commodities has attracted great attention since there are increasing demands (socially and economically) to develop renewable alternatives to fossil-derived fuels and chemicals. The primary drivers have been problems associated with over-reliance on fossil-derived fuels and chemicals as well as increased consumer awareness and demand for renewability and sustainability [1-3]. Lipid feedstocks have been considered as one of the biomass sources with the most potential for producing renewable liquid hydrocarbon products, which can be used as petroleum alternatives. The primary reason for this is the higher energy density [4] and relatively simpler structure [5] compared to other biomass feedstock such as lignocellulose.

Several lipid feedstocks are available for conversion to renewable liquid fuels including refined vegetable oils and animal fats (food grade), inedible plant oils (e.g., castor oil and Jatropha oil), and waste oils and fats such as brown grease, yellow grease, and sewage sludge lipids. The ability to utilize nonfood lipid feedstocks is important for process economics and commercial viability as feedstock cost 
accounts for anywhere between 40 and $80 \%$ of the production cost of renewable fuels [5-8]. Brown grease is a particularly attractive feedstock because its chemical reactions in the pyrolysis do not require high pressures, hydrogen, or expensive metal catalysts to produce hydrocarbons, thus greatly reducing the capital costs of a potential industrial process [9].

Brown grease is a plentiful source of low-grade waste oil. The term brown grease refers to a mixture of waste vegetable oils, animal fats, and grease that collect in the sewer lines and enter the wastewater treatment plants. Depending on the source, it is usually about $90 \%$ saturated and unsaturated free fatty acid, with smaller amounts of triglycerides. The ratios of fatty acids and triglycerides vary with source $[10,11]$. A primary source is a grease that is dumped down drains or from washing dishes. Sewer line deposits are formed as calcium ions leach from concrete pipes and react with the fatty acids, forming insoluble fatty acid calcium salts [12]. Brown grease is often incinerated or landfilled as a nuisance byproduct of the sewage treatment process. Most of the previous attempts to obtain a higher value fuel have focused on anaerobic digestion to biogas, or esterification to biodiesel $[10,11,13,14]$. Brown grease can also undergo pyrolysis to a kerosene-like mixture of hydrocarbons under relatively mild conditions [15-17]. The pyrolysis reaction, our concern, is defined as a high-temperature reaction in the absence of oxygen [18-21].

Yoke-Leng Sim and co-authors [9] found that brown grease breaks down into a mixture of alkanes and alkenes at temperatures above $300^{\circ} \mathrm{C}$ without the addition of hydrogen or an external catalyst. They performed pyrolysis experiments in order to accomplish a better understanding of the process of this reaction. In addition to brown grease, they performed the pyrolysis of palmitic and oleic acids as a model system for the saturated and unsaturated fatty acids in brown grease, respectively. They also found that three kinds of reaction pathways had taken place in the pyrolysis process: palmitone formation, decarboxylation, and decarbonylation reactions. Firstly, palmitone formation is consistent with partial conversion of palmitic acid to ketene, followed by reaction of another molecule of palmitic acid with the elimination of carbon dioxide [10]. The proposed reaction sequence of palmitic acid to produce palmitone is shown in Scheme 1. The ketene derived from palmitic acid has been trapped with aniline, forming the N-phenylamide [9]. In this work, Pathways A1 and A2 involve the formation of ketene; then, it undergoes a nucleophilic attack to produce palmitone via the enol form, as shown in Scheme 1.

Another interesting point that was found in the article is that although palmitic acid is unreactive below $300^{\circ} \mathrm{C}$, it appears to react at that temperature in the presence of oleic acid. This was explained in terms of radicals produced from allylic cleavage of unsaturated fatty acids, which may extract a hydrogen atom from the saturated acids, generating a reactive carboxyl radical [22]. It is probable that radicalpromoted decarboxylation reactions compete with ketone formation, yielding more hydrocarbons and less ketone byproduct. The proposed reaction pathway for palmitic acid in the presence of unsaturated acid-derived radicals is illustrated in Scheme 2.

Finally, decarbonylation has taken place where some evolution of $\mathrm{CO}$ was observed and the yield of hydrocarbons increased with a decrease in palmitone formation [23-26]. Brown grease normally contains trace amounts of iron, which appears to catalyze the decarbonylation reaction. Decarbonylation also occurs in the absence of iron but to a lesser extent. In other words, iron-catalyzed reactions compete with ketone formation, yielding more hydrocarbons and less ketone byproduct. Based on the experiments, Scheme 3 was proposed for the reaction pathway for palmitic acid.

It is clear from the experimental studies of brown grease pyrolysis that the product distribution is dependent on both the temperature and the heating profile $[9,15,22]$. Other experimental and theoretical studies on brown grease separation and flow have been performed [27, 28].

From a theoretical point of view, there are no previous investigations for the pyrolysis mechanisms of brown grease. In this work, a detailed computational study on the pyrolysis reactions in the absence of $\mathrm{Fe}$ (III) and in the presence of unsaturated fatty acid which is oleic acid was carried out. This study will provide a better understanding of the pyrolysis mechanisms. It will also provide insight into the effects of different heating profiles on the product distribution. This could be fulfilled by demonstrating the possible pyrolysis reaction mechanisms of the pyrolysis of the brown grease to increase our understanding of each investigated reaction kinetically and thermodynamically, and moreover to deeply understand the different reaction pathways mechanisms to produce several hydrocarbons and ketones under different conditions in order to mimic the experimental results of these reactions by getting the most feasible pathway and products using several accurate theoretical levels of theory.

The calculations below investigate radical mechanisms for fatty acid pyrolysis and nonradical mechanisms for ketone formation. Our attempts to co-pyrolyze palmitic acid and brown grease with waste polystyrene did not generate additional fatty acid products from radical reactions. Instead, these experiments acted as a fortuitous mechanistic probe that demonstrates reduced reactivity of the fatty acids by radical mechanisms, reduced radical fragmentation of the fatty acid radicals to lower mass fatty acids, and enhanced ketone production by a nonradical mechanism. With both pure palmitic acid and brown grease samples, the ketone byproducts increased significantly, with a concurrent decrease in the homologous series of alkanes and alkenes below 15 carbon atoms. These results are consistent with inhibition of the radical formation and/or reactions by polystyrene or its decomposition products, and thus supportive of radical mechanisms for these processes. The latter are styrene, toluene, ethylbenzene, isopropylbenzene, and $\alpha$-methylstyrene, in addition to some diphenylalkanes as minor products. It has been previously shown that attempted copolymerization of mono-unsaturated fatty acid methyl esters results in polymerization of the styrene, with little reaction with the fatty acid double bonds [29]. This is apparently a 


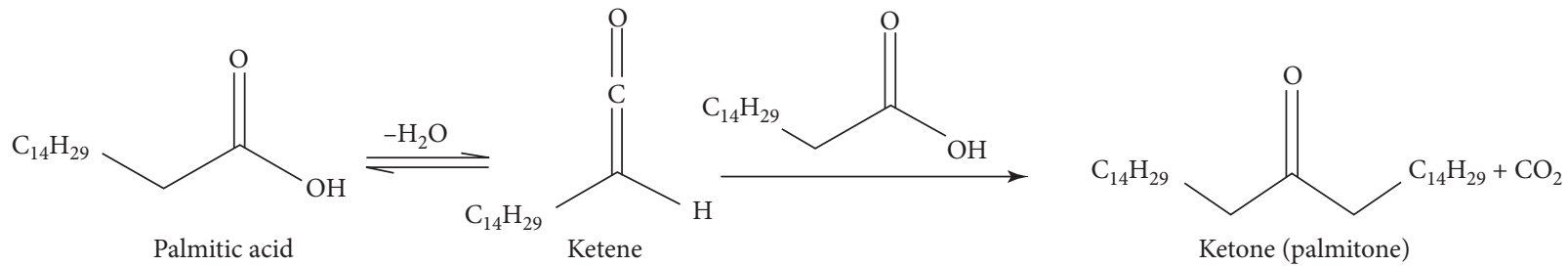

Scheme 1: The conversion reaction of palmitic acid to palmitone (Pathways A1 and A2).

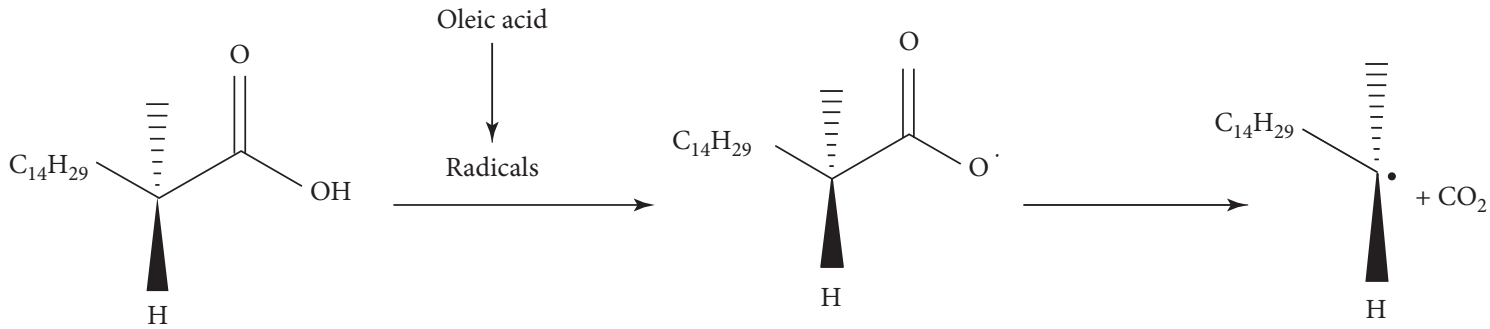

Scheme 2: Proposed reaction pathway for saturated fatty acids in the presence of radicals generated from unsaturated acids (Pathway B).

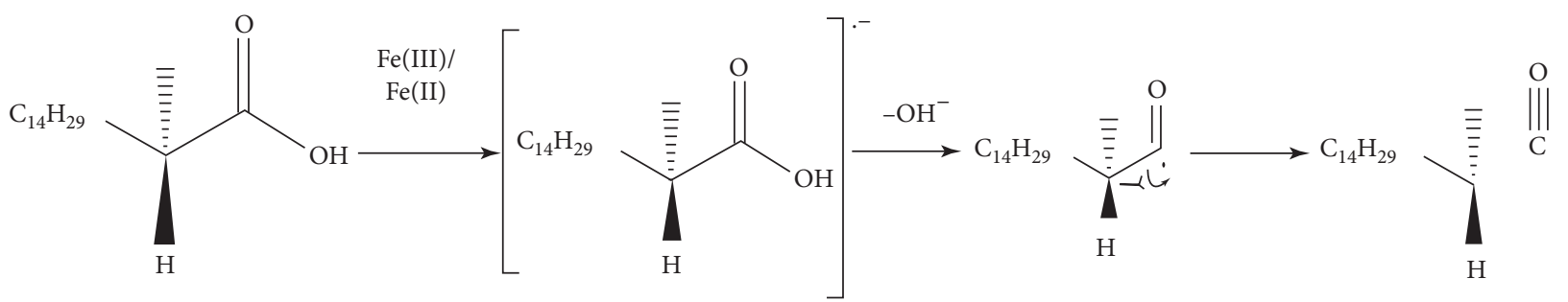

Scheme 3: Proposed reaction mechanism for palmitic acid (Pathway C).

result of the greater stability of the benzylic radicals formed from styrene polymerization. Likewise, radicals formed from polystyrene pyrolysis are likely to quench those formed from allylic cleavage of fatty acids, thus inhibiting the radical pathway.

\section{Computational Methods}

All calculations were performed using the Gaussian-16 [30] package. Based on the size of the system for the pyrolysis of brown grease, the DFT method is the most appropriate and worthy of the level of accuracy and computational cost. The geometry optimizations and harmonic vibrational frequency calculations of all stationary and saddle points have been performed at B3LYP [31] and composite method M06-2X [32] using B3LYP/6-31G(d) and B3LYP/6-31 + G(d) levels of theory for nonradical pathways and at uB3LYP/6-31G(d) for radical pathways. The relative energies of all stationary points in the vacuum were corrected with zero-point vibrational energies. For all proposed mechanisms, the transition states were analysed using the intrinsic reaction coordinate (IRC) [33-39], at B3LYP/6-31G(d) and uB3LYP/6-31G(d) levels of theory for nonradical and radical pathways, respectively, to affirm the linkage between the reactant and each of the required intermediate or product. Structures obtained from IRC were optimized to identify the minima to which each transition state is connected. Frequencies were calculated for all structures to ensure the absence of imaginary frequencies in the minima and the presence of only one imaginary frequency (one negative eigenvalue) in the transition structures.

\section{Results and Discussion}

The calculated reaction mechanism for Pathways A1 and A2 is outlined in Scheme 1 and presented in detail in Scheme 4. The optimized structures of each reactant $(\mathrm{R})$, intermediate (I), transition state (TS), and product (P) for the first and subsequent steps in Pathways A1 and A2 are shown in Figures 1 and 2, respectively. The potential energy diagram (PED) using the two DFT functionals can be found in Figures 3 and 4 . The thermodynamic parameters (relative energies $(\Delta E)$, enthalpies $(\Delta H)$, and Gibbs energies $(\Delta G))$ for the investigated pathways in $\mathrm{kJ} \mathrm{mol}^{-1}$ at $298.15 \mathrm{~kJ}$ and the kinetic parameters (activation energies $\left(E_{\mathrm{a}}\right)$, enthalpies of activation $\left(\Delta H^{\ddagger}\right)$, and Gibbs energies of activation $\left.\left(\Delta G^{\ddagger}\right)\right)$ are given in Tables 1 and 2 for Pathways A1 and A2. The conformational changes were considered for the palmitic acid to see if there is an influence on the reaction of potential 
Pathway A1

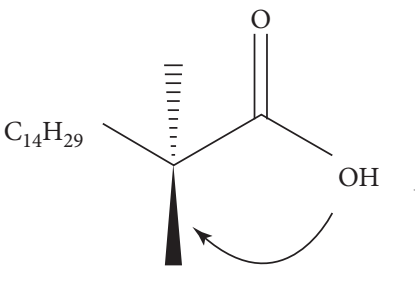

$\mathrm{H}$

Palmitic acid

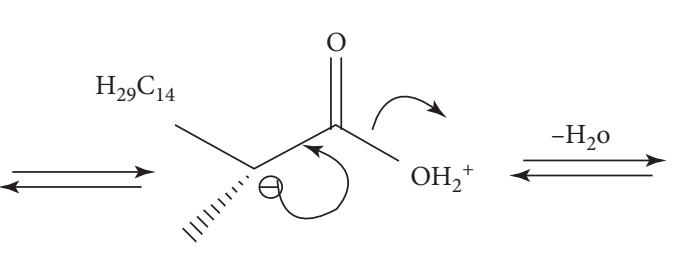

IAI

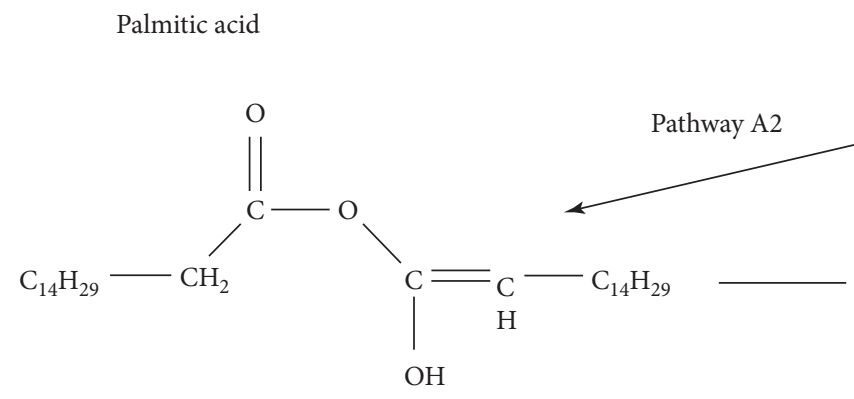

RA2 (Enol form)

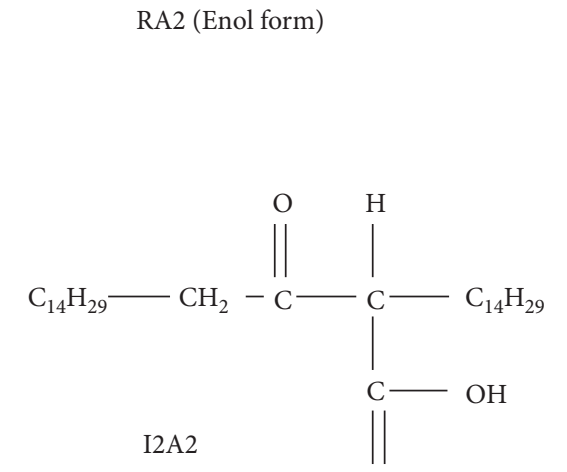

O

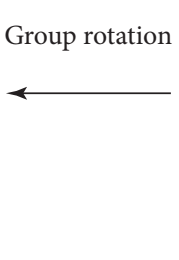

$-\mathrm{CO}_{2}$

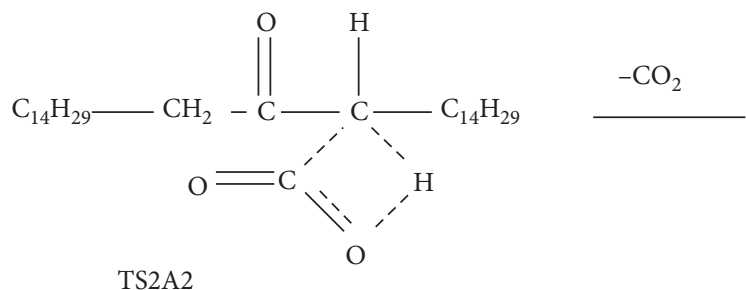

Scheme 4: The reaction mechanisms for palmitone formation from palmitic acid (Pathways A1 and A2).

energies. These conformers were found to be very comparable in terms of the energy differing by no more than $17 \mathrm{~kJ}$ $\mathrm{mol}^{-1}$; see Supporting Information (SI), Figure S1. However, the most stable conformer (R1) was used (Figure S1). Cartesian coordinates for all saddle and stationary points of each proposed pathway at certain levels of theory are reported in the Supporting Information.

\subsection{PED for the Proposed Reaction Mechanisms for Palmitic} Acid (Pathways A1 and A2). Pathways A1 and A2 represent the palmitone formation reaction from palmitic acid, which is depicted in Scheme 4. The proposed reaction is a multistep mechanism. The first step, depicted as Pathway A1, represents the ketene formation. It involves a nucleophilic attack by the $\mathrm{OH}$ (carboxylic) at the $\alpha$-acidic hydrogen atom of palmitic acid, thus resulting in an ionic carbon atom adjacent to the carbonyl group as well as a good leaving group $\left(\mathrm{OH}_{2}^{+}\right)$. The activation energies of the first step, TSA1 Ketene, are 320,317 , and $336 \mathrm{~kJ} \mathrm{~mol}^{-1}$ at B3LYP/6-31G(d), B3LYP/6-31 + G(d), and M062x/6-31G(d), respectively, as shown in Figure 2. The PED shows very similarly kinetic and thermodynamic results with both the B3LYP and M06-2X methods, as reported in Tables 1 and 2, where all proposed 


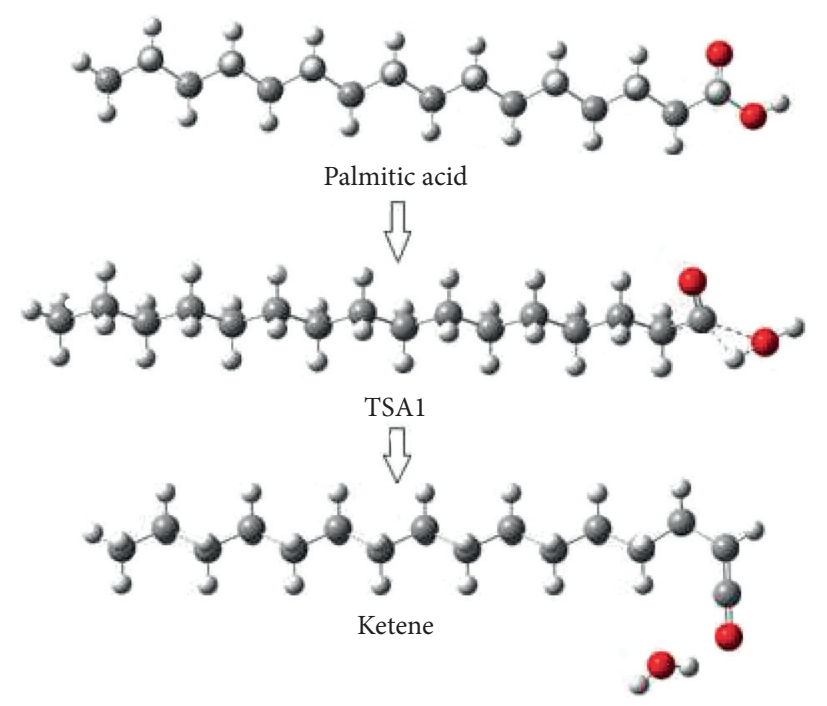

Figure 1: The optimized structures for palmitone formation from palmitic acid (Pathway A1).

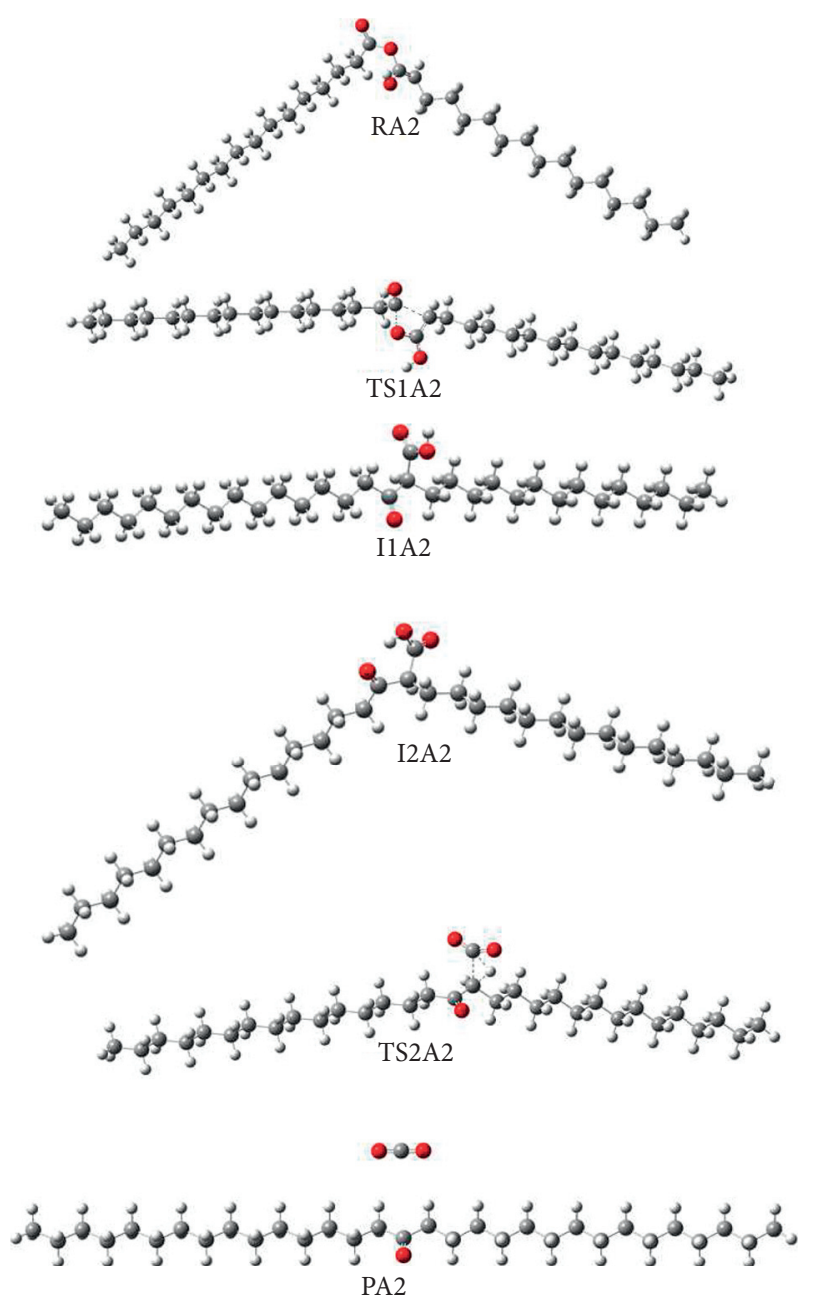

FIGURE 2: The optimized structures for palmitone formation via enol form of the palmitic acid-ketene adduct (Pathway A2).

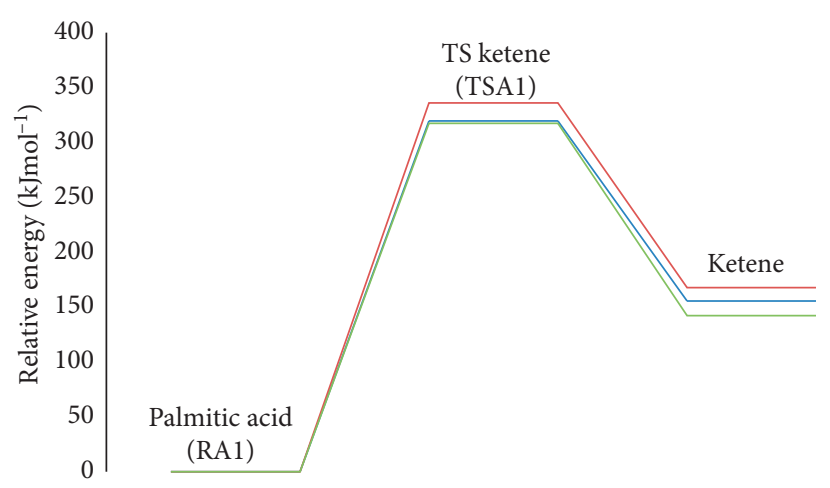

FIGURE 3: PED for ketone formation (Pathway A1). Relative energies calculated at B3LYP/6-31G(d) (blue line), B3LYP/6$31+\mathrm{G}(\mathrm{d})$ (green line), and M062x/6-31G(d) (red line).

methods nearly completely overlap. Accordingly, it could be seen that the addition of diffuse function noticeably changed the Gibbs energy of palmitone formation step by decreasing the energy up to $63 \mathrm{~kJ} \mathrm{~mol}^{-1}$.

In Pathway A2, the enol form of the palmitic acid-ketene adduct (RA2) rearranges to a $\beta$-ketoacid (I1A2) via transition state TS1A2. This undergoes a conformational change to I2A2, with a very negligible barrier, in which the carboxylate proton is coordinated to the keto-oxygen. Decarboxylation occurs via transition state TS2A2 forming the final palmitone product (PA2); see Scheme 4.

The kinetic parameters show that the activation energies for the first saddle point (TS1A2) are 118, 123, and $133 \mathrm{~kJ}$ $\mathrm{mol}^{-1}$ at B3LYP/6-31G(d), B3LYP/6-31+G(d), and M062x/ 6-31G(d), respectively. The barrier is considerably increased in decarboxylation step (TS2A2) compared to the first step with activation energy values of 289 and $304 \mathrm{~kJ} \mathrm{~mol}^{-1}$ at 


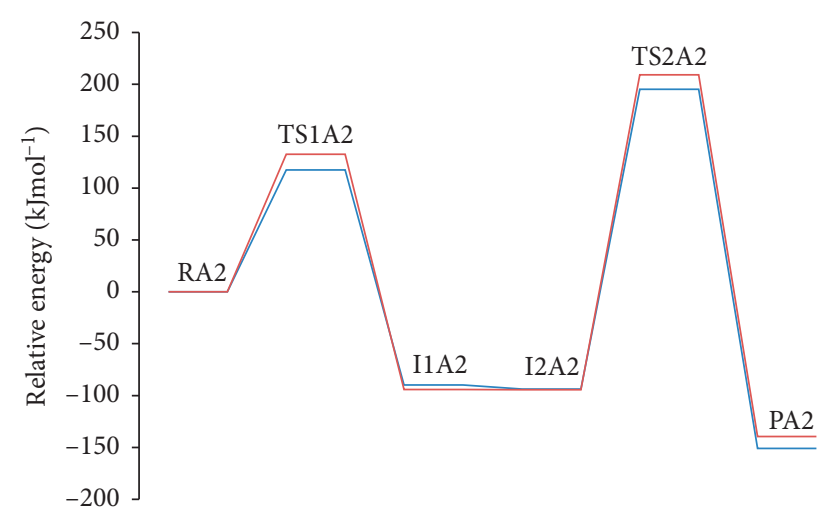

FIGURE 4: PED for palmitone formation via enol form of the palmitic acid-ketene adduct (Pathway A2). Relative energies calculated at B3LYP/6-31G(d) (blue line), B3LYP/6-31 + G(d), and M062x/6-31G(d) (red line).

TABLE 1: Activation energies and Gibbs energies of activation for the converting of palmitic acid to palmitone in $\mathrm{kJ} \mathrm{mol}^{-1}$ at $298 \mathrm{~K}$ (Pathways A1 and A2).

\begin{tabular}{lcccr}
\hline \multirow{2}{*}{ Level of theory } & \multicolumn{2}{c}{ Ketene formation (TSA1) } & \multicolumn{2}{c}{ Palmitone formation (TS2A2) } \\
& $E^{a}$ & $\Delta G^{*}$ & $E^{a}$ & 195 \\
B3LYP/6- & 320 & 321 & 204 & 197 \\
B3LYP/6- & 317 & 319 & 209 & 204 \\
M06-2X/6- & 336 & 337 & 208 \\
\hline
\end{tabular}

TABLE 2: Relative energies, enthalpies, and Gibbs energies for the converting of palmitic acid to palmitone in kJ mol-1 at $298 \mathrm{~K}$ (Pathways A1 and $\mathrm{A} 2$ ).

\begin{tabular}{lcccc}
\hline & & B3LYP/6-31G(d) & B3LYP/6-31+G(d) & M06-2X/6-31G(d) \\
\hline \multirow{3}{*}{ Ketene formation } & $\Delta E$ & -121 & -57 & -93 \\
& $\Delta H$ & -121 & -57 & -88 \\
\hline \multirow{3}{*}{ Palmitone formation } & $\Delta G$ & -122 & -59 & -135 \\
& $\Delta E$ & -151 & -149 & -139 \\
& $\Delta H$ & -146 & -148 & -135 \\
\hline
\end{tabular}

B3LYP/6-31G(d) and M062x/6-31G(d), respectively (Figure 4), which is the rate-determining step. However, the overall activation energy values are 195, 204, and $209 \mathrm{~kJ}$ $\mathrm{mol}^{-1}$ at B3LYP/6-31G(d), B3LYP/6-31 + G(d), and M062x/ 6-31G(d), respectively. Moreover, the thermodynamic results indicate that Pathway A2 is an exothermic reaction with a Gibbs energy of $-171,-159$, and $-150 \mathrm{~kJ} \mathrm{~mol}^{-1}$ at B3LYP/6-31G(d), B3LYP/6-31 + G(d), and M062x/6-31G(d), respectively (Table 2 ).

3.2. Overview of Radical Reactions in Brown Grease Pyrolysis. Thermal cleavage of unsaturated fatty acids is well known, and the resulting radical species can react in several ways, as illustrated in Table 3. It has been experimentally observed that brown grease pyrolysis generates $\mathrm{CO}, \mathrm{CO}_{2}$, and small amounts of other compounds. These observations support the results in Table 3, which shows the calculated enthalpies of typical radical reactions of the radical species described above.
The free energies will vary only slightly with chain length; therefore, reactions of three and four carbon species were calculated for simplicity and computational economy. Calculations were performed in the gas phase and in ethyl acetate, a solvent of medium polarity similar to the mixture of species in brown grease. Once formed, the alkyl radical, represented here by the propyl radical, may equilibrate with alkanes or extract a hydrogen atom from the carboxyl group. The carboxyl radical may eliminate $\mathrm{CO}_{2}$, regenerating the alkyl radical in a chain reaction (Pathway $\mathrm{B}$ ), as illustrated in the first two rows of Table 3. This energetically favourable process steadily produces $\mathrm{CO}_{2}$, as was observed experimentally. Alternatively, the alkyl radical may abstract a hydroxyl radical from the fatty acid, forming the aldehyde radical, which eliminates $\mathrm{CO}$ and regenerates the alkyl radical. This is an endothermic process, and the calculated enthalpy is consistent with spurts of $\mathrm{CO}$ evolution accompanied by a temperature drop in the reactor. The aldehyde radical can also react with an alkane, forming traces of aldehydes. 
TABLE 3: Calculated radical reactions of fatty acids at B3LYP/6-31G*.

\begin{tabular}{|c|c|c|c|c|c|c|}
\hline & & Reac & & & $\Delta$ Hgas $^{*}$ & Notes \\
\hline $\mathrm{C}_{3} \mathrm{H}_{7} \mathrm{COOH}$ & $\mathrm{C}_{3} \mathrm{H}_{7}$ & $\longrightarrow$ & $\mathrm{C}_{3} \mathrm{H}_{7} \mathrm{COO} \bullet$ & $\mathrm{C}_{3} \mathrm{H}_{8}$ & $-3.7(-1.2)$ & \\
\hline $\mathrm{C}_{3} \mathrm{H}_{7} \mathrm{COO} \bullet$ & & $\longrightarrow$ & $\mathrm{C}_{3} \mathrm{H}_{7} \bullet$ & $\mathrm{CO}_{2}$ & $-45.5(-35.2)$ & $\mathrm{a}$ \\
\hline $\mathrm{C}_{3} \mathrm{H}_{7} \mathrm{COOH}$ & $\mathrm{C}_{3} \mathrm{H}_{7}$ & $\longrightarrow$ & $\mathrm{C}_{3} \mathrm{H}_{7} \mathrm{CO} \cdot$ & $\mathrm{C}_{3} \mathrm{H}_{7} \mathrm{OH}$ & $69.9(67.1)$ & $\mathrm{b}$ \\
\hline $\mathrm{C}_{3} \mathrm{H}_{7} \mathrm{CO} \bullet$ & & $\longrightarrow$ & $\mathrm{C}_{3} \mathrm{H}_{7} \bullet$ & $\mathrm{CO}$ & $60.0(67.1)$ & c \\
\hline $\mathrm{C}_{3} \mathrm{H}_{7} \mathrm{CO} \cdot$ & $\mathrm{C}_{3} \mathrm{H}_{8}$ & $\longrightarrow$ & $\mathrm{C}_{3} \mathrm{H}_{7} \bullet$ & $\mathrm{C}_{3} \mathrm{H}_{7} \mathrm{CHO}$ & $54.1(51.3)$ & $\mathrm{d}$ \\
\hline
\end{tabular}

${ }^{*}$ Values in parenthesis are in ethyl acetate. a, $\mathrm{CO}_{2}$ observed in pyrolysis; b, traces of alcohol formed in pyrolysis; $\mathrm{c}$, large temperature drops during spurts of $\mathrm{CO}$ evolution; $\mathrm{d}$, traces of aldehydes formed in pyrolysis.
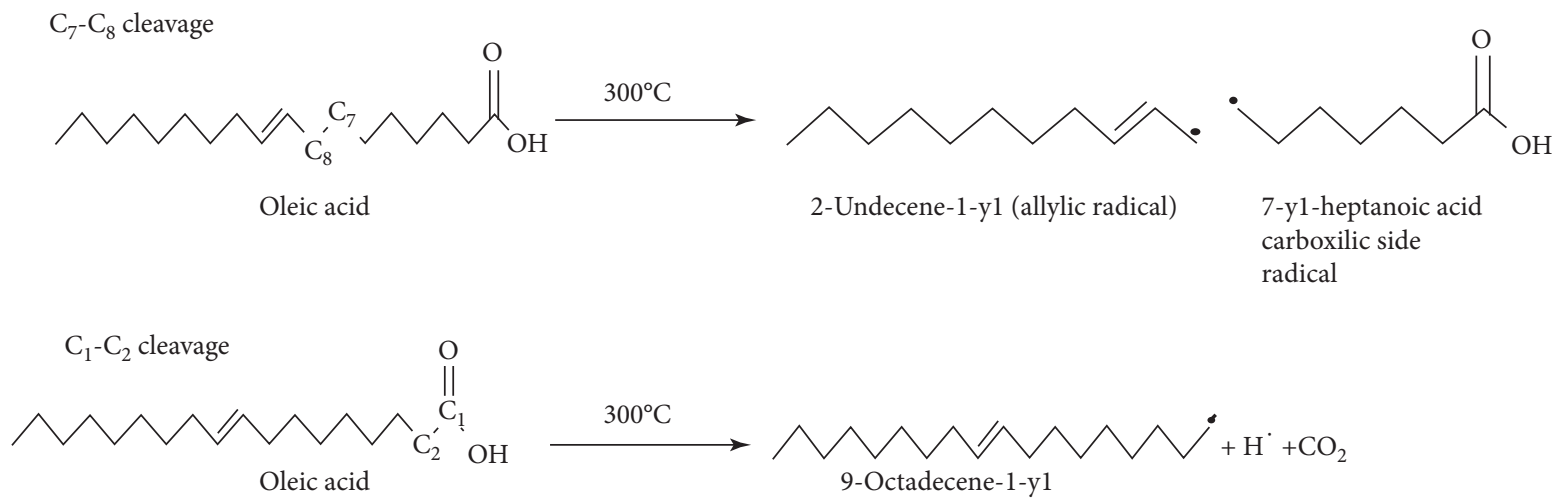

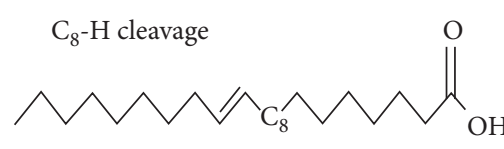

Oleic acid

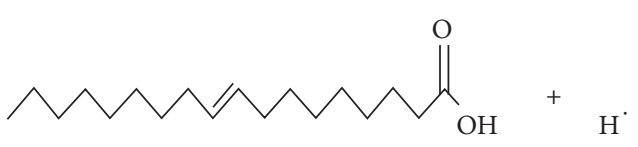

8-y1-9-Octadecenenoic acid

Scheme 5: The formation of radicals from the pyrolysis of oleic acid (Pathway B).

These reactions, forming Pathway $\mathrm{C}$, are represented by the last three rows of Table 3 .

\subsection{PED for the Proposed Reaction Mechanism (Pathway B)} for Palmitic Acid in the Presence of Radicals Generated from Unsaturated Acids. Pentadecane formation reaction from palmitic acid has been studied. The possible oleic acid-derived radical formation pathways are presented in Scheme 5, and the optimized geometries are shown in Figure 5. Pyrolysis of oleic acid reactions to produce five different types of radicals was investigated.

Pyrolysis of palmitic acid in the presence of oleic acid leads to a series of alkanes and alkenes. This pathway can be initiated by radicals that resulted from the pyrolysis of the oleic acid process. The pyrolysis of oleic acid produces several possible radicals from the dissociation reactions that involve $\mathrm{C}-\mathrm{H}, \mathrm{C}-\mathrm{O}$, and $\mathrm{C}-\mathrm{C}$ bond homolytic cleavage, followed by radical equilibration. Previous studies reported that there were several reasons that influence the pyrolysis of oleic acid selectivity towards fatty acids and hydrocarbons products, such as the presence and position of the double bond and the number of bond dissociation energies $[40,41]$.
Hartgers et al. [40] reported that, due to the lower bond dissociation energy of the $\mathrm{C}-\mathrm{C}$ bond compared to $\mathrm{C}-\mathrm{H}$ and $\mathrm{C}-\mathrm{O}$, initiation of the pyrolysis reaction involves homolytic cleavage of the $\mathrm{C}-\mathrm{C}$ bond rather than $\mathrm{C}-\mathrm{H}$ or $\mathrm{C}-\mathrm{O}$ bonds. Additionally, the presence of oxygen (electron-withdrawing atoms) in the carboxyl group weakens the C-C bond adjacent to the carboxyl group. Therefore, the initiation of pyrolysis was likely to involve homolytic cleavage of this $\mathrm{C}-\mathrm{C}$ bond. This study focuses on an interesting, special homolytic cleavage (allylic C-H bond cleavage), which produces the $\mathrm{H}$ and the allylic radicals. However, generating many potential kinds of radicals from oleic acid will be discussed at the beginning of this section.

The thermodynamic parameters in Table 4 indicate that all the three bonds dissociation reactions are endothermic where the heat of reaction values are varied within 283$-374 \mathrm{~kJ} \mathrm{~mol}^{-1}$. The bond dissociation reaction is a one-step reaction mechanism. Based on the results shown in Table 4, the activation energy of $\mathrm{C}_{7}-\mathrm{C}_{8}$ (allylic position) cleavage reaction is the lowest among others which is $376 \mathrm{~kJ} \mathrm{~mol}^{-1}$ compared to 447 and $400 \mathrm{~kJ} \mathrm{~mol}^{-1}$ for $\left(\mathrm{C}_{1}-\mathrm{C}_{2}\right)$ and $\left(\mathrm{C}_{8}-\mathrm{H}\right)$ cleavage reactions, respectively; see Figure 6.

Radical formation from unsaturated fatty acids, illustrated by oleic acid, occurs at elevated temperatures from 


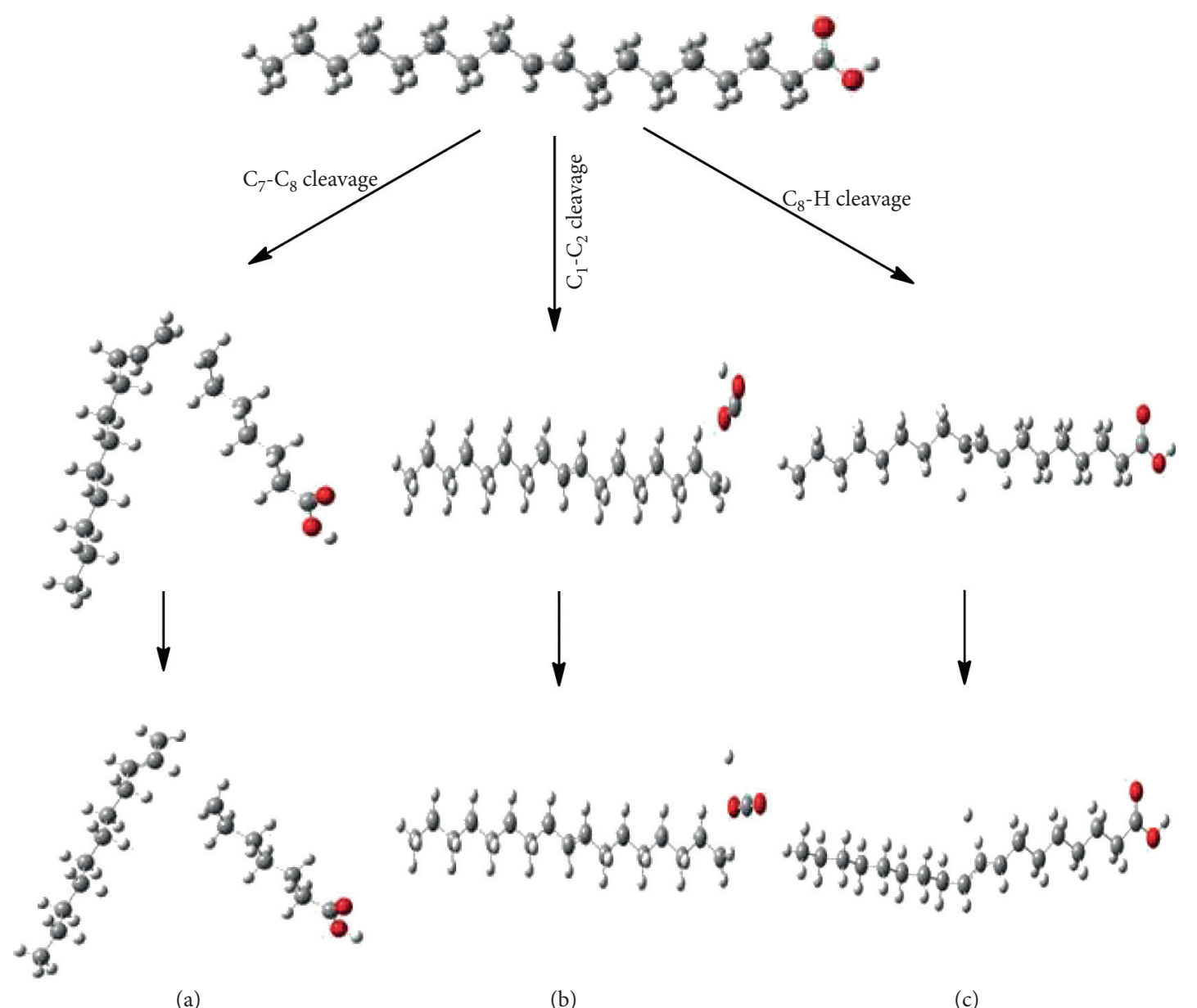

Figure 5: The optimized structures for (a) $\mathrm{C}_{7}-\mathrm{C}_{8}$ cleavage, (b) $\mathrm{C}_{1}-\mathrm{C}_{2}$ cleavage, and (c) $\mathrm{C}_{8}$-H cleavage (the first step in pathway (B) at uB3LYP/6-31G(d)).

TAвLE 4: Relative energies, enthalpies, Gibbs energies, activation energies, and Gibbs energies of activation for the dissociation reactions of oleic acid at uB3LYP/6-31G(d) (in $\mathrm{kJ} \mathrm{mol}^{-1}$ ) at $298 \mathrm{~K}$.

\begin{tabular}{|c|c|c|c|c|c|}
\hline Type of dissociation & $\Delta E$ & $\Delta H$ & $\Delta G$ & $\Delta E^{f}$ & $\Delta G^{\neq}$ \\
\hline$\left(\mathrm{C}_{7}-\mathrm{C}_{8}\right)$ cleavage & 276 & 283 & 245 & 376 & 364 \\
\hline$\left(\mathrm{C}_{1}-\mathrm{C}_{2}\right)$ cleavage & 362 & 374 & 329 & 447 & 442 \\
\hline$\left(\mathrm{C}_{8}-\mathrm{H}\right)$ cleavage & 332 & 337 & 323 & 400 & 390 \\
\hline
\end{tabular}

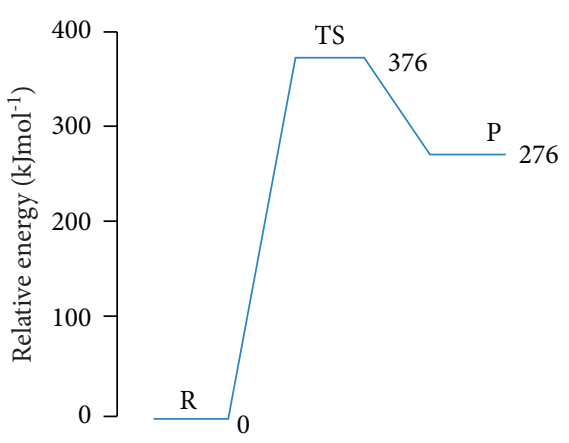

(a)

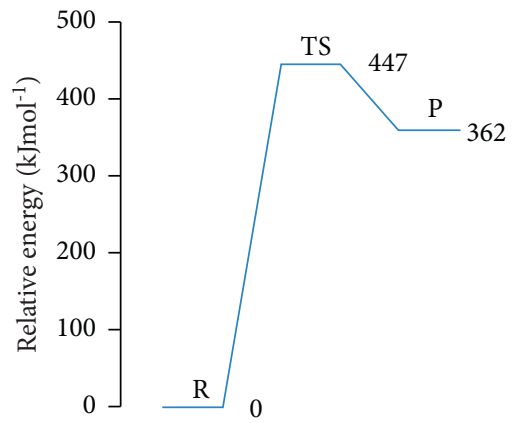

(b)

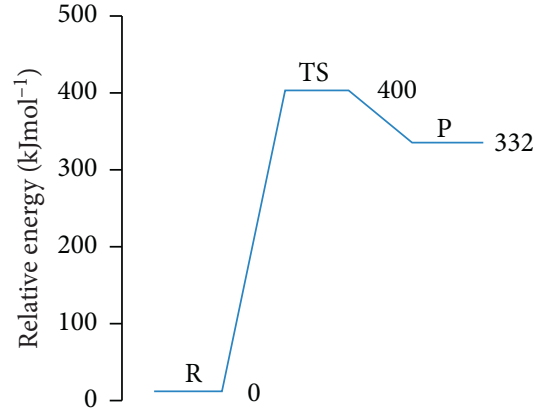

(c)

Figure 6: PED for the pyrolysis of the oleic process for (a) $C_{7}-C_{8}$ cleavage, (b) $C_{1}-C_{2}$ cleavage, and (c) $C_{8}-H$ cleavage. 


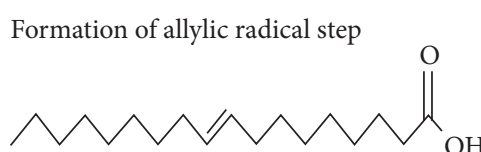

Oleic acid

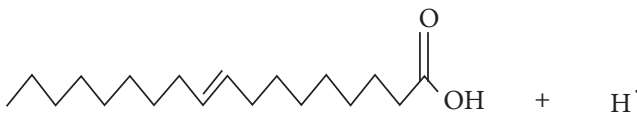

8-y1-9-Octadecenoic acid

Hydrogen radical (allylic radical)<smiles>CCCCCCCCCCCCCCCCCCC(=O)C(=O)O</smiles>

Oleic acid

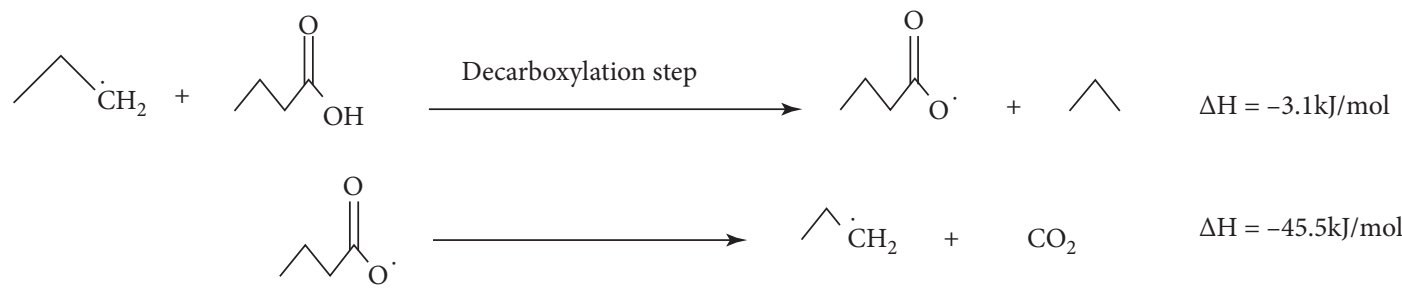

Scheme 6: Radical formation reactions and decarboxylation chain reaction (Pathway C).

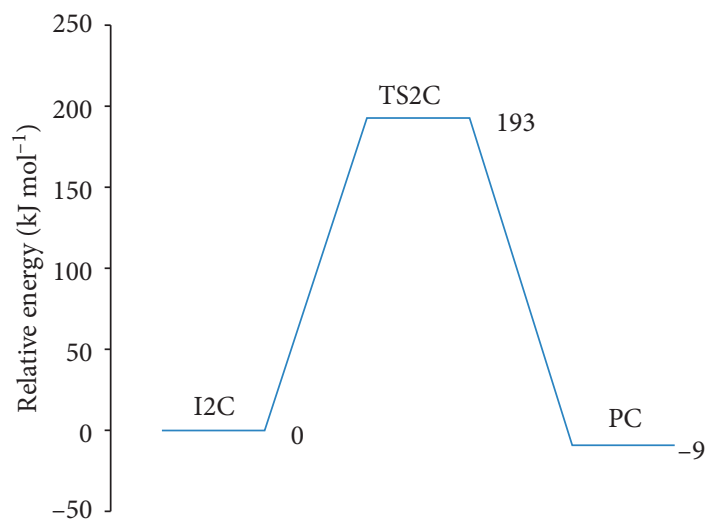

Figure 7: PED for pentadecane formation (Pathway C) (the second step).<smiles>CCCC(=O)[C+](CCC)C(=O)CCC</smiles><smiles>CCCC(=O)CC[CH2+]C(C)=O</smiles><smiles>CCCCCCCC(=O)CCC</smiles>

Scheme 7: Radical reactions forming CO and minor pyrolysis byproducts (Pathway D). 
hydrogen loss or abstraction, or by allylic cleavage of the fatty acid chain, as shown in Scheme 6. These radicals will equilibrate under the reaction conditions, ultimately leading alkanes and alkenes from $\mathrm{C} 7$ to more than $\mathrm{C} 17$, with some gas containing small hydrocarbons, $\mathrm{CO}$, and $\mathrm{CO}_{2}$. The relative energies of radical formation by fatty acid bond cleavage are shown in Table 4, with the lowest energy being from allylic bond cleavage.

Subsequent radical reactions with fatty acids (Pathway C) react in a probable chain reaction, illustrated by the propyl radical and butanoic acid in the lower part of Scheme 6. The activation energy for the second step of pentadecane formation (Pathway C) is $193 \mathrm{~kJ} \mathrm{~mol}^{-1}$, as shown in Figure 7. Other radical reactions are possible (Pathway D), again illustrated by the propyl radical and butanoic acid in Scheme 7 . These account for the observed evolution of carbon monoxide and the minor alcohol and aldehyde pyrolysis byproducts.

Pathway D results in the loss of CO from an aldehyde radical and formation of trace amounts of alcohols and aldehydes in the hydrocarbon product. Although hydrogen atom extraction from the fatty acid is energetically favored over hydroxyl group extraction, the latter is the only explanation for the observed bursts of $\mathrm{CO}$ evolution. At temperatures at or above $300^{\circ} \mathrm{C}$, there is sufficient thermal energy to overcome an energy barrier of $60 \mathrm{~kJ} / \mathrm{mol}$. Additional experimental evidence is the observation that the reaction temperature drops by 10 degrees or more during the spurts of $\mathrm{CO}$ evolution, determined by a gas analyser at the output of the reactor.

\section{Conclusion}

The chemical reactions for the pyrolysis of brown grease (palmitic acid) have been studied using computational quantum chemistry, and all observed products can be explained. Pathways A1 and A2 are a nonradical mechanism that occurred via two key steps. It begins with ketene formation (Pathway A1) with the activation energies (for TSA1) being 320,317 , and $336 \mathrm{~kJ} \mathrm{~mol}^{-1}$ at B3LYP/6-31G(d), B3LYP/6-31 + G(d), and M062x/6-31G(d) levels of theory, respectively. This is followed by an addition to a second molecule of fatty acid with $\mathrm{CO}_{2}$ elimination (Pathway A2), the stable ester intermediate, which is the fastest step, and finally decarboxylation step. The enthalpy of ketene formation in the gas phase is $-121,-57 \mathrm{~kJ} \mathrm{~mol}^{-1}$, and $-88 \mathrm{~kJ}$ $\mathrm{mol}^{-1}$ for Pathway A1, whereas in Pathway B it is -146 , -148 , and $-135 \mathrm{~kJ} \mathrm{~mol}^{-1}$ at B3LYP/6-31G(d), B3LYP/6$31+\mathrm{G}(\mathrm{d})$, and M062x/6-31G(d), respectively.

Alkane formation mechanism (Pathways $\mathrm{C}$ and $\mathrm{D}$ ) has two main steps. The first step is the pyrolysis of oleic acid to produce radicals (rate-determining step) with an activation energy of $400 \mathrm{~kJ} \mathrm{~mol}^{-1}$ at uB3LYP/6-31G(d). The second step is the radical's attack on the palmitic acid followed by decarboxylation to produce pentadecane with an activation energy of $193 \mathrm{~kJ}$ $\mathrm{mol}^{-1}$ at uB3LYP/6-31G(d). Based on the results, it can be concluded that the decarboxylation reaction (Pathway $\mathrm{C}$ ) is an exothermic reaction; therefore, it is more favourable. Furthermore, hydrogen and an expensive metal catalyst such as platinum group are not required to produce hydrocarbons from brown grease, thus greatly reducing the capital costs of a potential industrial process. The knowledge gained in this study will surely aid in the development of an industrial brown grease pyrolysis process.

\section{Data Availability}

All data used to support the findings of this study are available in the article and in the supplementary materials.

\section{Conflicts of Interest}

The authors declare no conflicts of interest.

\section{Acknowledgments}

MHA is grateful to the Deanship of Research at the University of Jordan for financial support. This work was supported in part by NSF grant \#CBET 1802524. The authors are grateful to Compute Canada for computer time. The authors acknowledge Huy Ngoc Nguyen (Ho Chi Minh University of Science) for technical assistance.

\section{Supplementary Materials}

The conformational changes for the palmitic acid and Cartesian coordinates for the proposed pathways (Pathways $\mathrm{A} 1, \mathrm{~A} 2, \mathrm{~B}$, and C) of the pyrolysis of brown grease reaction. (Supplementary Materials)

\section{References}

[1] X. Miao, Q. Wu, and C. Yang, "Fast pyrolysis of microalgae to produce renewable fuels," Journal of Analytical and Applied Pyrolysis, vol. 71, no. 2, pp. 855-863, 2004.

[2] A. Ajanovic, "Renewable fuels-a comparative assessment from economic, energetic and ecological point-of-view up to 2050 in EU-countries," Renewable Energy, vol. 60, pp. 733-738, 2013.

[3] A. K. Azad and M. R. Islam, "A renewable alternative bio-fuel source from Jatropha curcus seeds oil: performance and emission study for DI diesel engine," International Journal of Advanced Renewable Energy Researches, vol. 1, no. 2, pp. 126-132, 2012.

[4] J. A. Spring, "Thermal cracking of lipids to produce renewable fuels and platform chemicals," Doctoral Dissertation, University of Alberta, Edmonton, Canada, 2014.

[5] S. Popov and S. Kumar, "Renewable fuels via catalytic hydrodeoxygenation of lipid-based feedstocks," Biofuels, vol. 4, no. 2, pp. 219-239, 2013.

[6] I. M. Atadashi, M. K. Aroua, A. R. Abdul Aziz, and N. M. N. Sulaiman, "Production of biodiesel using high free fatty acid feedstocks," Renewable and Sustainable Energy Reviews, vol. 16, no. 5, pp. 3275-3285, 2012.

[7] J. Hill, E. Nelson, D. Tilman, S. Polasky, and D. Tiffany, "sciences of the USA 11206-11210," Proceedings of the National Academy of Science, vol. 103, no. 30, 2006.

[8] J. M. Marchetti, V. U. Miguel, and A. F. Errazu, "TechnoEconomic study of different alternatives for biodiesel production," Fuel Processing Technology, vol. 89, no. 8, pp. 740-748, 2008. 
[9] Y.-L. Sim, N. Meyappan, N. S. Yen et al., "Chemical reactions in the pyrolysis of Brown grease," Fuel, vol. 207, pp. 274-282, 2017.

[10] T. K. Gurung, A. A. Casazza, B. Aliakbarian, E. Finocchio, P. Perego, and G. Busca, "Catalytic conversion of ethyl acetate and acetic acid on alumina as models of vegetable oils conversion to biofuels," Chemical Engineering Journal, vol. 215216, pp. 838-848, 2013.

[11] O. Roman, B. Heyd, B. Broyart, R. Castillo, and M.-N. Maillard, "Oxidative reactivity of unsaturated fatty acids from sunflower, high oleic sunflower and rapeseed oils subjected to heat treatment, under controlled conditions," LWT-Food Science and Technology, vol. 52, no. 1, pp. 49-59, 2013.

[12] X. He, F. L. De Los Reyes, M. L. Leming et al., "Mechanisms of Fat, Oil and Grease (FOG) deposit formation in sewer lines," Water Research, vol. 47, no. 13, pp. 4451-4459, 2013.

[13] P. M. L. Ward, "Brown and black grease suitability for incorporation into feeds and suitability for biofuels," Journal of Food Protection, vol. 75, no. 4, pp. 731-737, 2012.

[14] C. D. Hurd and K. E. Martin, "Ketene from acetic acid," Journal of the American Chemical Society, vol. 131, 1929.

[15] J. Strothers, R. B. Matthews, A. Toney et al., "Hydrocarbon fuel from Brown grease: effects of reaction temperature profile on yields and product distribution," Fuel, vol. 239, pp. 573578, 2019.

[16] L. M. Burns, T. Pinnock, K. Amoa et al., "Beneficial use of Brown grease: a source of petroleum-derived hydrocarbons," New England Water Environment Association Journal, vol. 48, no. 2, p. 44, 2014.

[17] K. K. Georgieff, "Preparation of ketene from glacial acetic acid. Methyl acetate, and ethyl acetate," Canadian Journal of Chemistry, vol. 30, no. 4, pp. 332-347, 1952.

[18] A. V. Bridgwater, "Review of fast pyrolysis of biomass and product upgrading," Biomass And Bioenergy, vol. 38, pp. 68-94, 2012.

[19] A. A. Lappas, E. F. Iliopoulou, K. Kalogiannis, and S. Stefanidis, " 15 conversion of biomass to fuels and chemicals via thermochemical processes," Biorefinery, vol. 35, 2012.

[20] M. Balat, "Mechanisms of thermochemical biomass conversion processes. Part 1: reactions of pyrolysis," Energy Sources, Part A: Recovery, Utilization, and Environmental Effects, vol. 30, no. 7, pp. 620-635, 2008.

[21] M. H. Almatarneh, L. Barhoumi, B. Al-Tayyem et al., "Computational study for the second-stage cracking of the pyrolysis of ethylamine: decomposition of methanimine, ethenamine, and ethanimine," Computational and Theoretical Chemistry, vol. 1075, pp. 9-17, 2016.

[22] D. H. R. Barton, H. A. Dowlatshahi, W. B. Motherwell, and D. Villemin, "A new radical decarboxylation reaction for the conversion of carboxylic acids into hydrocarbons," Journal of the Chemical Society, Chemical Communications, vol. 15, no. 15 , pp. 732-733, 1980.

[23] J. Fu, X. Lu, and P. E. Savage, "Hydrothermal decarboxylation and hydrogenation of fatty acids over Pt/C," Chemsuschem, vol. 4, no. 4, pp. 481-486, 2011.

[24] I. Simakova, O. Simakova, P. Mäki-Arvela, A. Simakov, M. Estrada, and D. Y. Murzin, "Deoxygenation of palmitic and stearic acid over supported Pd catalysts: effect of metal dispersion," Applied Catalysis A: General Journal, vol. 21, 2009.

[25] J. G. Immer, M. J. Kelly, and H. H. Lamb, "Catalytic reaction pathways in liquid-phase deoxygenation of C18 free fatty acids," Applied Catalysis A: General, vol. 375, no. 1, pp. 134-139, 2010.
[26] M. Arend, T. Nonnen, W. F. Hoelderich, J. Fischer, and J. Groos, "Catalytic deoxygenation of oleic acid in continuous gas flow for the production of diesel-like hydrocarbons," Applied Catalysis A: General, vol. 399, no. 1-2, pp. 198-204, 2011.

[27] A. V. Radulescu, D. Bonneau, and M. Hajjam, "A theoretical study of two-dimensional grease flow in regions with discontinuities," Lubrication Science, vol. 15, no. 2, pp. 163-171, 2003.

[28] Q. Tu, J. Wang, M. Lu, A. Brougham, and T. Lu, “A solventfree approach to extract the lipid fraction from sewer grease for biodiesel production," Waste Management, vol. 54, pp. 126-130, 2016.

[29] S. A. Harrison and W. E. Tolberg, "Peroxide catalyzed polymerization of styrene in pure fatty methyl esters," Journal of the American Oil Chemists Society, vol. 30, no. 3, pp. 114-117, 1953.

[30] G. W. Frisch, H. B. Schlegel, G. E. Scuseria et al., Gaussian 16, Rev. A.03, Gaussian, Inc., Wallingford, CT, USA, 2016.

[31] W. Kohn, A. D. Becke, and R. G. Parr, "Density functional theory of electronic structure," The Journal of Physical Chemistry, vol. 100, no. 31, pp. 12974-12980, 1996.

[32] Y. Zhao and D. G. Truhlar, "The M06 suite of density functionals for main group thermochemistry, thermochemical kinetics, noncovalent interactions, excited states, and transition elements: two new functionals and systematic testing of four M06-class functionals and 12 other functionals," Theoretical Chemistry Accounts, vol. 120, no. 1-3, pp. 215-241, 2008.

[33] K. Fukui, "The path of chemical reactions-the IRC approach," Accounts of Chemical Research, vol. 14, no. 12, pp. 363-368, 1981.

[34] H. P. Hratchian and H. B. Schlegel, "Accurate reaction paths using A hessian based predictor-corrector integrator," The Journal of Chemical Physics, vol. 120, no. 21, pp. 9918-9924, 2004.

[35] H. O. Oh, A. I. Alrawashdeh, M. H. Almatarneh, and R. A. Poirier, "Computational study on the deamination reaction of adenine with $\mathrm{OH}-/ \mathrm{n} \mathrm{H} 2 \mathrm{O}(\mathrm{n}=0,1,2,3)$ and 3H2O," Canadian Journal of Chemistry, vol. 91, no. 7, 2013.

[36] M. H. Almatarneh, R. Al Omari, R. A. Omeir et al., "Computational study of bimolecular decomposition reactions of propylamine," Scintific Report, vol. 10, no. 1-12, Article ID 11698, 2020.

[37] S. E. Rawadieh, I. S. Altarawneh, M. A. Batiha, L. A. AlMakhadmeh, M. H. Almatarneh, and M. Altarawneh, "Reaction of hydroperoxy radicals with primary C1-5 alcohols: a profound effect on ignition delay times," Energy \& Fuels, vol. 33, no. 11, pp. 11781-11794, 2019.

[38] M. Altarawneh, A. A. H. Al-Muhtaseb, M. H. Almatarneh, R. A. Poirier, N. W. Assaf, and K. K. Altarawneh, "Theoretical investigation into competing unimolecular reactions encountered in the pyrolysis of acetamide," The Journal of Physical Chemistry A, vol. 115, no. 48, pp. 14092-14099, 2011.

[39] M. Altarawneh, M. H. Almatarneh, A. Marashdeh, and B. Z. Dlugogorski, "Decomposition of ethylamine through bimolecular reactions," Combustion and Flame, vol. 163, pp. 532-539, 2016.

[40] W. A. Hartgers, J. S. Sinninghe Damsté, and J. W. De Leeuw, "Curie-point pyrolysis of sodium salts of functionalized fatty acids," Journal of Analytical and Applied Pyrolysis, vol. 34, no. 2, pp. 191-217, 1995.

[41] L. Dandik and H. A. Aksoy, "Effect of catalyst on the pyrolysis of used oil carried out in a fractionating pyrolysis reactor," Renewable Energy, vol. 16, pp. 1007-1010, 1999. 